\title{
Analysis a project at learner used collaboration of educational process promote collaboration application
}

\author{
Tamás Szimkovics \\ Faculty of Informatics, University of Debrecen \\ szimkovics.tamas@gmail.com
}

\begin{abstract}
E-learning systems are used in many areas such as: organizational learning, self-education, open and distance education. The education based on new interactive electronic systems is often used in frontal form. This form of education may be inefficient in public education.

In present study we examine the opportunities of the most popular open source e-learning systems which promote the communication and collaboration, and which tools can support the information exchange between teacherstudent and student-student.

We compare the following e-learning systems (LCMS, Learning Content Management Systems): Moodle, ATutor, Ilias, Claroline. We present those free tools which help the project education, and can be easily integrated into the LCMS.
\end{abstract}

Keywords: collaboration, LMS, project methodology

\section{Introduction}

The world of teaching and learning is changed in the knowledge-based society. The help of e-learning opened a variety of options for those who want to learn, but the tutors also should adapt to the changing tendencies. Now the tutors are not necessarily the main sources of knowledge, and it is no longer sufficient for the tutors to guide students, they should help in learning activities of students.

Instead face-to-face educational applications, such as Web 2.0, the possibilities of dynamic tools can greatly contribute to the effectiveness of education. In light 
of the new opportunities the teacher-student collaboration is redefined. Education management processes provide appropriate frameworks for the use of new tools. Worldwide one of the most effective method for organizing educational process is project work in small groups, which is also based on collaboration. [1]

\section{Using projects for organizing educational pro- cesses}

The project is for organizing educational processes when a course of education is based on solving practical problems.

Important to mention two names linked to the development of the project educational process. The first John Dewey, American philosopher and educational reformer, professor of the University of Chicago, who created the foundations of project method in his laboratory school during the last years of nineteenth century. The second is the student and follower of Dewey, William Kilpatrick (1871-1965). He defined the project method, its theoretical foundations and practical use. The characteristics of organizing a project of educational process:

- Specific learning technology, the main source of knowledge based on experience as an individual and as in group;

- Students try to discover as much as possible connections and linking points of a problem;

- Instead of passively receiving and processing practices, students try to have new types of behavior and develop their existing skills;

- The main value of the project method is the process: the thinking process, the experience gained during the implementation of practical activities, impact of mental and emotional experiences. [2]

If we transplant these characteristics into LCMS systems, we can organize a high-quality and effective education.

\section{Learning Managment System}

There are many free e-learning systems with access to dynamic collaborative work tools. Wecompered four of them: Moodle, ATutor, Ilias and Claroline. All the mentioned systems have open source code. A few words about them:

Moodle was originally developed by the Australian Martin Dougiamas WebCT administrator. He wanted to help teachers create online courses, which would focus on the collaboration and collective building of content.

Creators of ATutor system played close attention to write a software, which is complied with the W3C and WCAG standards. ATutoris compatible with all 
common curriculum packages. The interface provides a barrier-free access (for hearing and visually impaired users).

The Ilias system gives tools for creating a complete virtual school. Within the system it is easy to personalize the workspace.

The construction of Claroline system was launched in the pedagogical faculty of Louvain Catholic University. The system is suitable for managing more courses at the same time and for monitoring the students' online activities, both in individual and statistical manner.[4]

\subsection{Integrated collaboration tools in e-learning system}

In the LCMS system mentioned above the following collaborational tools can be integrated:

- the forum is an asynchronous communication facility, where participants can ask questions and answer to each other;

- chat is a simple, real-time, synchronous communication tool. In supported instant messaging service we can write in chat applications, not integrated to the educational system, such as Skype, ICQ, Yahoo, etc .;

- wiki tools are suitable for collecting knowledge on a particular topic. As tutors, we can monitor content editing, but we can transfer the task for our students too. Articles appearing in the wiki will behave in the curricula automatically as links. If you encounter an unfamiliar concept, with one click, you can read the wiki article for it;

- we can create groups. This can be useful, if some courses we want to keep in more groups, or within groups we want to create smaller groups. This tool can be important part of the project work, and also may promote differentiated education.

Integrated systems only a small part the collaboration tools, which can be used. In the listed electronic education systems could be necessary to install other modules.

\subsection{Installable collaborative tools for e-learning frame system}

Installing the appropriate modules can provide the following services: audio and video call, multi-user real-time graphical and textual editing and creating mind maps. We would like to present a bit more options mentioned above systems.

The video call implements a synchronous communication. In addition, in the audio and video channels they often provide text chat. In each e-learning system mentioned above can be found this function, but generally you must install a separate module. The video calling provides one-way or two-way communication:

- one person broadcast everyone - one-way (live streaming); 
- one person talking to one person - two-way (discussion, video call);

- everyone communicates with everyone - two-way (video conference, teamwork).

Some applications are managing multiple information channels. One of the most popular and interactive tools is the BigBlueButton. It is an independent virtual classroom application, which has modules for almost all of these e-learning systems. The BigBlueButton application is suitable to keep online conferences and lectures. In this case, the communication is supported by web camera and microphone. We can hear and see the lecturer, in addition, it is possible to draw explanations on slide show in real-time. During the broadcast the participants can use text chat to communicate with each other. The presenter can broadcast his/her desktop for all participants to show the content. The presenters and the conference administrators have possibility to control which participants can post a comment to the lecture. Presentations will be recorded and may be shared with those who were unable to join the live broadcast.

The online text editors can become integral parts of collaborative education. There are two free applications that can be implemented and most widely used: the Etherpad [6] and Google Docs [5]. These online applications allow to edit documents by several users in real time. It is a faster and more transparent way for creating a document than sending files to a group of students. A further advantage of similar applications is that they help the tutor to easily check and correct the works of a student or a group of students. Team members can invite each other into a group for a brainstorming or for a specific cooperative activity. In realtime editors mentioned above the participants can also communicate by chat. The changes made during the construction of a document are saved and can be seen afterwards. These applications are helping to overcome the obstacles raised by distances when working in group.

Among real-time collaborational tools the mind-mapeditors are worth mentioning too. Group work can be a great tool, in which a project can be designed visually in schematic form. The educational mind map is effective because it is built on associations, so the new knowledge is more easily fixed. On the other hand, the visual appearance of verbal information involves the both hemispheres of the brain at the same time. [7] In the Moodle system there is a module for this purpose. Mind maps help you create cooperatively as well. In addition, many similar online applications can be found on the Internet, such as MindMup (Figure 1).

It can be seen, that the project educational process is versatile. It is assisted with LMS systems and using free tools as well. Unfortunately, we did not find these resources complete in all systems. We grouped (Table 1) the available options of LMS systems for collaboration. 


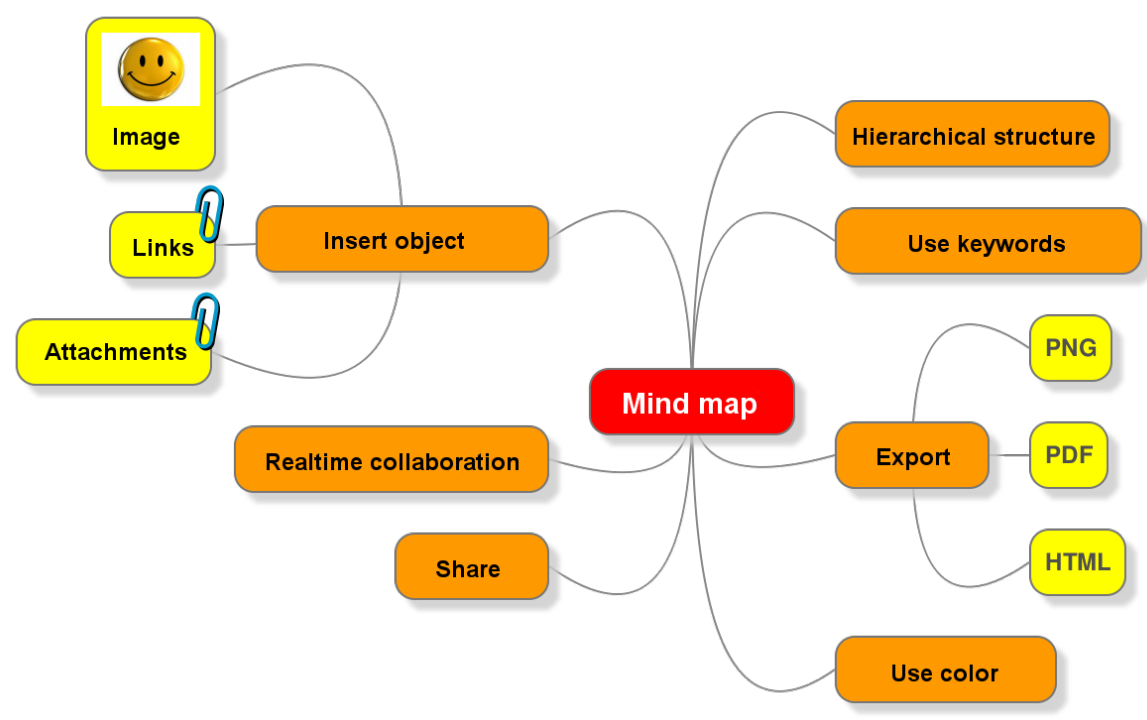

Figure 1: Mind map made using MindMup

\begin{tabular}{|l|l|l|l|l|}
\hline & ATutor & Claroline & Ilias & Moodle \\
\hline Video call & $\checkmark$ & $\checkmark$ & $\checkmark$ & $\checkmark$ \\
\hline BBB & $\checkmark$ & x & $\checkmark$ & $\checkmark$ \\
\hline Mind map & x & x & x & $\checkmark$ \\
\hline Real-time text editor & x & x & $\checkmark$ & $\checkmark$ \\
\hline Instant messaging & $\checkmark$ & x & $\checkmark$ & $\checkmark$ \\
\hline
\end{tabular}

Table 1: The collaborative possibilities of investigated LMS systems

\section{Summary}

Due to comparing the referred LMS systems, we can conclude that the aTutor and Claroline systems are less supported with embedded communication modules. In the Moodle system the support is the highest. The Ilias system is also has a great potential, but it has not so many modules.

It is important, to take into consideration that not only the number of tools prevails in usability of e-learning system. The services must be achieved easily. Important also is to learn the usage of them in fast and easy way.

The built of educational system must be ergonomic with the tools in it. For example, the Moodle system can be used in many ways, but from another point of view, it can be too complicated and difficult to use for beginners. Therefore, students might tend to circumvent using the embedded tools. 
From the educational point of view, although it is distance learning, the teacher has to fulfill the role of the tutor and sometimes hold on the management of the projects. In case of many groups it requires experienced teachers and lot of work. In return, the students get real experience in solving problems, and also learn how to work in team.

The number of distance learning students is growing, and probably similar applications will be essential in education between students and teachers and among students in geographically dispersed classes.

In the near future we will analyze the usability of some popular and useful tools of collaboration using by test groups.

\section{References}

[1] Laszlo Varallyai, Miklos Herdon, Application Web technologies and collaborative tools in education Information Technology in Higher Education, 2008 http://www . agr. unideb.hu/if2008/kiadvany/papers/C51.pdf

[2] Ivan Falus, Didactics - Theory of teaching learning, National Textbook Publishing, 2004

[3] Dr. Ilma Kovach, The e-learning is becoming more diverse, The Hungarian Institute of Culture and Lectorate of Fine Arts, in press. 32-34. 2010 http://epa.niif.hu/ 01300/01306/00108/pdf/EPA01306\_Szin\_2010\_15\_06.pdf

[4] ANDREw BARD, E-learning solutions - The Claroline educational framework, Learning on the Web 85-86, 2006 http://epa.oszk.hu/02000/02051/00005/pdf/ EPA02051/_Tudomanyos_Kozlemenyek_14_085-188.pdf

[5] Conner, N., Google Apps: The Missing Manual, O'Reilly Media, 2008 http://cdn. oreillystatic.com/oreilly/booksamplers/5_Google_Apps_TMM_Sampler.pdf

[6] Вов Pүмм, Lyn Hay's Etherpads Using Collaborative Platforms for Learn-ing in the LIS Distance Education Course, iConference 2013, 995-998, https://www.ideals . illinois.edu/bitstream/handle/2142/42090/495.pdf? sequence=2

[7] Eve Gyarmathy, Mind map, TaniTani, 2001, 108-115, http://www.ekt.bme.hu/ BeruTerv/gondolatterkep.pdf 